\title{
Health professionals', expert patients' and dieters' beliefs and attitudes about obesity.
}

\author{
McConnon A, Gribble R, Raats MM, Stubbs J, Shepherd R
}

\begin{abstract}
$\underline{\text { Abstract }}$
Background: Research has suggested that patients and treatment providers hold different beliefs and models of obesity. This could impact consistency and quality of interventions for weight management. This study investigated the attitudes and beliefs of health professionals, commercial weight management advisors (expert patients) and overweight and obese dieters, towards obesity.
\end{abstract}

Methods: Data were collected using a self-administered questionnaire from 287 health professionals, 85 expert patients and 116 dieters. Respondents gave their views on obesity causation and consequences, and the most efficacious means to manage obesity. Demographic data and selfreported height and weight were also collected. Factor analysis, ANOVA and t-tests were used to analyse the data.

Results: Health professionals, expert patients and dieters held similar models of obesity, identifying the same causes (lifestyle causes), consequences (medical consequences) and treatments (currentrecommended options) of obesity/overweight.

Conclusion: This study indicated broad similarity between beliefs and attitudes of those involved in obesity treatment and those they aim to treat than previously suggested. The concordance of beliefs between patients and treatment providers is an encouraging finding and may have important implications for public health strategies in this area.

\section{Introduction}

Research has suggested that biases and differences between patient and provider models of disease could have major implications for care and the success, or perceived success, of treatment (Starfield, 1981, Harvey and Hill, 2001). Assessment of the lay group and GP beliefs regarding obesity shows that while lay people tend towards a biologically-based model of causality, GPs believe that social, structural, psychological and behavioural factors play a greater role and as a result, treatment would be more appropriate outside the medical sphere (Ogden and Flanagan, 2008). The models of obesity held by other health professionals such as practice nurses, dieticians and physical therapists follow a similar lifestyle/behavioural framework (Hoppé, 1997, Harvey et al., 2002, Barr, 2004, Sack, 2009). In order to move closer to patient-practitioner partnerships in the management of chronic relapsing conditions such as obesity, it is important to bring about greater consensus on the causes, effects and treatment options between different stakeholders.

This research aimed to ascertain the degree of similarity or dissimilarity in the beliefs regarding obesity of health professionals and non-experts providing services for treatment and management of obesity/overweight, as well as current dieters. 


\section{Materials and Methods}

\section{Recruitment}

Participants comprised three groups; health professionals with an interest in obesity (hereafter termed "health professionals"), commercial weight management advisors (hereafter termed "expert patients") and overweight and obese dieters. The health professionals group was composed of members of the organisation Dieticians in Obesity Management (DOM UK), and of the Association of the Study of Obesity UK, as well as primary care trust employees with a remit for nutrition, activity and weight control at the public health level. Expert patients were recruited from the commercial slimming organisation, Slimming World, UK. The dieters group was comprised of overweight individuals attempting to lose weight without formal supervision (e.g. not attending a health professional or slimming club) and were recruited from employees of the University of Surrey and the Surrey Research Park, Guildford. Participants were sent an email asking them to complete a webbased questionnaire, the link to which was provided within the email. Due to the method of recruitment used in this study (via emailing lists) it is not possible to know how many people received the invitation to participate in the study. This study was approved by the South West Surrey NHS Research Ethics Committee prior to recruitment.

\section{Questionnaire}

A web-based questionnaire was developed based on a questionnaire used by Ogden et al. 2001 (Ogden et al., 2001), along with consideration of a range of components described by the International Classification of Functioning, Disability and Health (ICF) Core Sets for obesity (Stucki et al., 2004). The ICF Core Sets provide an international, comprehensive framework to describe functioning and health in relation to a range of chronic diseases.

Data were collected on respondents' perceptions of models of obesity (causes, effects and treatment options). Using 5 point Likert scales, participants rated their level of agreement with a series of statements relating to obesity from "not at all" (score of 1 ) to "totally" (score of 5). Selfreported data on age, gender, marital status, highest educational level, weight and height were collected.

\section{Data analysis}

Data were analysed using SPSS for Windows, version 15. (SPSS, Chicago, IL). Descriptive statistics included means and standard deviations. Factor analysis was conducted using principal axis factoring (with Oblimin rotation). Cronbach alpha values $(\alpha)$ were inspected to confirm reliability of the factors and mean scores were calculated for each of the factors. Differences between the health professionals', expert patients' and dieters' beliefs were explored using Analysis of Variance. Posthoc tests (Tukey HSD) were used to describe the significance of differences between groups. BMI scores were calculated, using height and weight measurements.

\section{$\underline{\text { Results }}$}

A total of 488 people took part in the survey; 287 health professionals, 85 expert patients and 116 dieters. Eighty participants failed to provide their demographic details. All survey responses were used in analysis, regardless of completeness. Accordingly, results are presented as valid percentages. Table 1 presents the demographic profile of the populations surveyed.

Participants' beliefs about the possible causes, effects and treatment options for obesity are presented in Table 2. All groups viewed lifestyle and psychological factors as the most important causes of obesity and medical factors as the least important, however some differences between the 
respondent groups were apparent. Health professionals rated social factors ( $p \leq 0.001)$, expert patients rated lifestyle $(p \leq 0.01)$ and psychological $(p \leq 0.001)$ factors and dieters rated medical factors $(p \leq 0.001)$ as having a significantly greater role in the causation of obesity, when compared with the other two groups.

The perceived major effects of obesity on functioning and health were considered to be medical, self help/direct effects and psycho-sexual for all groups. When compared against the other groups, expert patients had significantly higher scores for the effects of obesity on psycho-sexual outcomes, mobility, coping with stress/pain and lifestyle/relationships issues $(p \leq 0.001)$, while dieters perceived medical ( $p \leq 0.01)$, mobility $(p \leq 0.001)$ and lifestyle/relationships issues $(p \leq 0.001)$ as being significantly less serious consequences. There were no significant differences between the groups for selfhelp/direct effects.

Current recommendations, based on behaviour change, for weight loss were rated as each group as the most effective treatment option for obesity and radical treatments as the least effective. Dieters' scores were significantly higher for recommended treatment than the other groups $(p \leq 0.01)$. Expert patients had a significantly lower score for social/psychological support options and the use of radical treatment options when compared with the other groups $(p \leq 0.001)$. There were no significant differences in beliefs about the role of medical professionals in managing obesity.

\section{Discussion}

Previous research has suggested that patients and treatment providers hold very different beliefs and models of obesity (Ogden et al., 2001), however the results of this analysis suggest that, in general, the different stakeholder groups rank factors associated with the causes, consequences and preferred treatment options for obesity in a similar order. These results give grounds for some degree of optimism as they illustrate a degree of consensus in beliefs about obesity between stakeholder groups, which could form the basis of co-operative action in obesity management.

The dieter's higher scores for medical factors stresses the persistence of biological and genetic causal models of illness within this group. Combined with dieters' high score for lifestyle factors, this may imply that people are fully aware of the impact of lifestyle choices on weight, yet they continue to view overweight/obesity as a sickness and therefore something beyond an individual's control. This fits in with other obesity frameworks and the known complexities of patient models of obesity (Ogden et al., 2001, Brown, 2006, Brogan, 2009, Wang, 2010). The causal model of health professionals places significantly greater prominence on social factors and less on medical factors in comparison to dieters and expert patients, a response to decades of research highlighting the role of lifestyle factors in obesity causation. Greener et al found a similar model of causation amongst health professionals and policy makers (Greener, 2010). There was considerable consensus between the three groups that changing modifiable lifestyle factors to be the leading treatment for obesity.

The health professionals and expert patient groups both represent samples with a direct interest in obesity treatment, who have been trained to work with overweight and obese individuals in their weight loss efforts. Therefore these groups may have a wider appreciation for the factors contributing to obesity and may be more likely to take into account and acknowledge the attitudes and beliefs of the obese, than other stakeholder groups involved in obesity treatment. Additionally, the dieters group were not representative of the general population with $90 \%$ of the sample being female and over a third having higher degrees. The nature of these samples may contribute to the concordance between groups revealed in this study. Caution should therefore be taken in generalising the results of this study and future research should look to explore if similar results are found in different study populations (e.g. males, dieters seeking professional help, alternative health professional groups). Bearing the above caveats in mind, a merging of patient and doctor beliefs and models of disease, regardless of the severity of an illness, has been shown to improve patient 
outcomes (Starfield, 1981, Bass, 1986), increase patient satisfaction (Carlsen and Aakvik, 2006) and reduce referrals to secondary sources (Carlsen et al., 2008). A concordance of viewpoints between treatment providers and patients may facilitate long-term efficient and successful treatment of overweight and obesity and may have important implications for public health strategy in this area.

\section{Source of Funding:}

This work was supported by a grant from the EU Food Quality and Safety Priority of the Sixth Framework Programme, contract no. FP6-2005-513946.

\section{Conflict of interest:}

JS is employed by the commercial slimming organisation, Slimming World.

\section{References:}

BARR, S., YARKER, K., LEVY-MILNE, R., CHAPMAN, G. (2004) Canadian dietitians' views and practices regarding obesity and weight management. Journal of Human Nutrition and Dietetics, 17, 503-512.

BASS, M., BUCK, C., TURNER, L., DICKIE, G., PRATT, G., ROBINSON, HC. (1986) The physician's actions and the outcome of illness in family practice. The Journal of Family Practice, 23, 43-47.

BROGAN, A., HEVEY, D. (2009) The structure of the causal attribution belief network of patients with obesity. British Journal of Health Psychology, 14, 35-48.

BROWN, I., THOMPSON, J., TOD, A., JONES, G. (2006) Primary care support for tackling obesity: a qualitative study of the perceptions of obese patients. British Journal of General Practice, 56, 666-72.

CARLSEN, B. \& AAKVIK, A. (2006) Patient involvement in clinical decision making: the effect of GP attitude on patient satisfaction. Health Expect 9, 148-157.

CARLSEN, B., AAKVIK, A. \& NORHEIM, O. (2008) Variation in Practice: A Questionnaire Survey of How Congruence in Attitudes Between Doctors and Patients Influences Referral Decisions. Med Decis Making., 28, 262.

GREENER, J., DOUGLAS, F., VAN TEIJLINGEN, E. (2010) More of the same? Conflicting perspectives of obesity causation and intervention amongst overweight people, health professionals and policy makers. Social Science and Medicine, 70, 1042-9.

HARVEY, E. \& HILL, A. (2001) Health professionals' views of overweight people and smokers. Int J Obes Relat Metab Disord., 25, 1253-1261.

HARVEY, E., SUMMERBELL, C., KIRK, S. \& HILL, A. (2002) Dietitians' views of overweight and obese people and reported management practices. J Hum Nutr Diet., 15, 331-347.

HOPPÉ, R., OGDEN, J. (1997) Practice nurses' beliefs about obesity and weight related interventions in primary care. International Journal of Obesity and Related Metabolic Disorders, 21, 141-146.

OGDEN, J., BANDARA, I., COHEN, H., FARMER, D., HARDIE, J., MINAS, H., MOORE, J., QURESHI, S., WALTER, F. \& WHITEHEAD, M. (2001) General practitioners' and patients' models of obesity: whose problem is it? Patient Educ Couns., 44, 227-233.

OGDEN, J. \& FLANAGAN, Z. (2008) Beliefs about the causes and solutions to obesity: a comparison of GPs and lay people. Patient Educ Couns., 71, 72. 
SACK, S., RADIER, DR., MAIRELLA, KK., TOUGER-DECKER, R., KHAN, H. (2009) Physical Therapists' Attitudes, Knowledge, and Practice Approaches Regarding People Who Are Obese. Physical Therapy, 89, 804-815.

STARFIELD, B., WRAY, C., HESS, K., GROSS, R., BIRK, PS., D'LUGOFF, BC. (1981) The influence of patient-practitioner agreement on outcome of care. American Journal of Public Health, 71, 127-31.

STUCKI, A., DAANSEN, P., FUESSL, M., CIEZA, A., HUBER, E., ATKINSON, R., KOSTANJSEK, N., STUCKI, G. \& RUOF, J. (2004) ICF Core Sets for obesity. Journal of Rehabilitation Medicine, 36, 107-113.

WANG, C., COUPS, EJ. (2010) Causal beliefs about obesity and associated health behaviors: results from a population-based survey. International journal of behavioural nutrition and physical activity, 3, 19. 